\title{
Recomendaciones para el uso de ventilación no-invasiva en COVID-19 ${ }^{+}$
}

\author{
MARÍA PAOLA ARELLANO M.*, ORLANDO DÍAZ P.*, PABLO NARBONA M.**, \\ MIGUEL AGUAYO C.***, JAVIER SALAS O.***, VÍCTOR LEIVA V.****, MARCIA AGUIRRE Z.*****, \\ CÉSAR MAQUILÓN O.******, FERNANDO VEGA G.*******, CRISTIÁN OLAVE C.********, \\ ARIEL CISTERNAS V.******** y MATÍAS FLORENZANO V.********
}

\section{Recommendations for using non-invasive ventilation in COVID-19 patients}

La pandemia COVID-19 ha tomado a los sistemas de salud del mundo por sorpresa. Ello ha derivado en una situación global de insuficiente disponibilidad de insumos médicos para cubrir las altísimas demandas por camas hospitalarias de mediana y alta complejidad. En este escenario, es perentorio el uso adecuado y compasivo de los recursos disponibles.

Una estrategia para subsanar la falta de ventiladores mecánicos de terapia intensiva, es el uso de equipos de presión positiva CPAP y BiPAP (CPAP, continuous positive airway pressure; BiPAP, bilevel positive airway pressure). Aunque no existen estudios randomizados que avalen su uso en COVID-19, existen publicaciones que demuestran que la terapia CPAP y la cánula de oxígeno de alto flujo son efectivas en la falla hipoxémica respiratoria aguda ${ }^{1,2}$. La terapia BiPAP tendría menos efecto, pudiendo ser incluso perjudicial y es menos recomendada en este escenario $^{3,4}$.

Clásicamente, la terapia CPAP/BiPAP se aplica con circuitos abiertos que producen dispersión de gotitas respiratorias ${ }^{5}$. Esto ha sido motivo de preocupación, pues pone en riesgo de infección al personal de salud ${ }^{6}$. Sin embargo, existen medidas específicas que disminuyen notoriamente este riesgo (ver más adelante). Otra preocupación de la terapia CPAP/BiPAP en distrés respiratorio agudo es el riesgo de barotrauma por "injuria pulmonar auto-inducida", al no proveer una ventilación controlada (protectora), especialmente si el equipo no permite la medición de volumen corriente. Asimismo, el riesgo de aspiración y la tolerancia a la terapia deben valorarse individualmente en cada paciente.

Durante esta pandemia, la terapia CPAP/BiPAP puede ser usada como prueba terapéutica bajo estricta monitorización. Sin embargo, es razonable pensar que su principal rol es servir como puente mientras un ventilador mecánico se hace disponible. Otra utilidad de la terapia CPAP/BiPAP es su empleo como techo terapéutico, cuando las condiciones o deseos del paciente aconsejen una limitación del esfuerzo terapéutico. Finalmente, la terapia CPAP/BiPAP se puede aplicar también durante la desconexión de ventilación mecánica (VM) en pacientes con riesgo de fracaso.

Respecto al uso crónico domiciliario de un dispositivo de presión positiva en pacientes portadores de apnea del sueño, se debe asumir

Sociedad Chilena de Medicina del Sueño - Sociedad Chilena de Enfermedades Respiratorias.

Santiago, 25 de mayo de 2020.

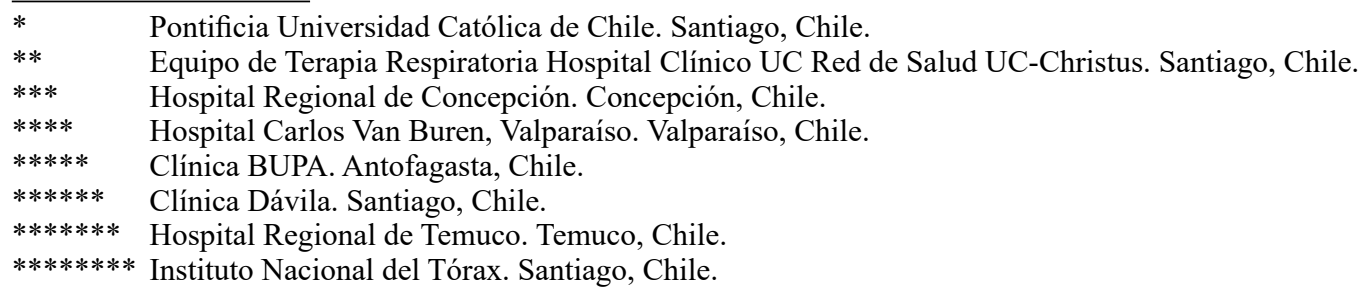


un alto número de portadores asintomáticos de COVID-19 y se debe intentar disminuir el riesgo teórico de aumento de aerosolización del virus en domicilio. Por esto, la Federación Latinoamericana de Sociedades de Sueño (FLASS) recomienda evitar el uso del humidificador del CPAP según tolerancia (o usarlo sin agua), al menos, durante la etapa aguda de esta pandemia, además de todas los cuidados domiciliarios ampliamente difundidos, en especial dormir aislado y airear la habitación ${ }^{8}$.

El objetivo de estas recomendaciones es ayudar en la protocolización del uso de la terapia CPAP/BiPAP en paciente con insuficiencia respiratoria aguda COVID-19 a fin de lograr los mejores resultados y reducir la posibilidad de infección nosocomial.

\section{Consideraciones generales}

1. La terapia con dispositivos de CPAP/BiPAP puede aplicarse en pacientes con COVID-19 en los siguientes escenarios: como terapia de prueba, como puente a un ventilador mecánico, como techo terapéutico y como ayuda a la desconexión del ventilador mecánico invasivo.

2. No todos los pacientes se benefician de los cuidados de terapia intensiva. Se deben establecer, en el momento oportuno, los límites del esfuerzo terapéutico con el paciente y sus familiares.

3. Utilizar apropiadamente todos los implementos de protección respiratoria y de contacto según las guías de comité de infecciones local.

4. Si se decide iniciar terapia con $\mathrm{CPAP} / \mathrm{Bi}$ PAP en insuficiencia respiratoria aguda por COVID-19, evaluar la respuesta en un plazo de 30-60 min. No retrase a más de $2 \mathrm{~h}$ la decisión de escalar a VM. El retraso en la conexión a VM está asociado a un aumento de la tasa de mortalidad 9 .

5. Los pacientes con COVID-19 pueden sufrir un deterioro rápido e inesperado. Por ello, deben ser monitorizados permanentemente, en unidades con personal capacitado.

6. El riesgo de generar aerosoles depende de una serie de variables: presiones utilizadas, fuga no intencional de aire, cooperación del paciente ${ }^{5,10,11}$.

7. Los pacientes hospitalizados con COVID-19 presentan insuficiencia respiratoria hipoxémica. La primera estrategia es la oxigenoterapia (incluyendo cánula nasal de alto flujo (CNAF). Si ella no es suficiente, continúe con la CPAP. La terapia con BiPAP debería reservarse para aquellos casos en que persista disnea o si existe hipercapnia.

8. Disminuya al mínimo las desconexiones del circuito de ventilación por riesgo de generación de aerosoles del virus.

9. No realice nebulizaciones. Si el paciente requiere broncodilatadores, utilice inhaladores de dosis medida. Alternativamente, puede utilizarse nebulizadores de malla vibratoria pues son herméticos.

10. Disminuya al máximo las interacciones entre el personal de salud y el paciente, especialmente aquellas a una distancia menor de 1 metro.

11. Utilice $\mathrm{O}_{2}$ suplementario seco. Evite el uso de humidificador de burbuja pues favorece la generación de aerosoles del virus. En el caso de los ventiladores sin mezclador de oxígeno, éste debe conectarse cerca de la máscara del paciente para optimizar la $\mathrm{FiO}_{2}$ entregada ${ }^{12}$.

12. Evite la humidificación activa pues el vapor de agua puede favorecer la generación de aerosoles del virus. Prefiera la humidificación pasiva con los intercambiadores de calor/humedad (HME). Asimismo, se pueden utilizar los filtros virales/bacterianos asociados HME, llamados HMEF (Heat and moisture exchanger filter).

13. Favorezca una ventilación sincrónica entre paciente y ventilador para promover el éxito de la intervención y disminuir el riesgo de dispersión de virus al ambiente.

14. La presencia de secreciones respiratorias abundantes, un mal mecanismo de la tos y/o la necesidad de aspiración son contraindicaciones para la terapia con CPAP/BiPAP.

15. Durante la conexión/desconexión de CPAP/ BiPAP pídale al paciente que evite hablar y toser. Aplique una mascarilla quirúrgica apenas el paciente se desconecte. La secuencia de acciones es:

- Colocar filtro a la mascarilla, ajustar la mascarilla al paciente, encender el equipo CPAP/BiPAP.

- Apagar el equipo CPAP/BiPAP, desconectarlo de la mascarilla, retirar la mascarilla con su filtro.

\section{Configuración del circuito en equipos de ventilación no invasiva}

1. Con el fin de disminuir el riesgo de dispersión del virus: el circuito debe estar configurado por una mascarilla facial $u$ oronasal no ventilada, es decir, sin orificios de fuga intenciona- 
da (se reconoce por el codo azul), conectada a un filtro viral/bacteriano antes de la salida de aire por el puerto espiratorio (Figura 1).

- No utilice máscaras nasales ni almohadillas nasales. La máscara debe cubrir nariz y boca.

- Las mascarillas ventiladas están contraindicadas en COVID-19 pues pueden favorecer la dispersión del virus hasta una distancia de 1 metro del enfermo 5 .

2. Los equipos de ventilación mecánica no invasiva con turbina, idealmente deben equiparse con 3 filtros: 1) filtro HEPA (High Efficiency Particulate Air) entre el puerto inspiratorio y el ventilador, para evitar la contaminación cruzada (mandatorio); 2) filtro HMEF cerca de la máscara del paciente (mandatorio) y 3 ) filtro HEPA entre el puerto espiratorio y el ventilador (opcional) (Figura 2).
3. Es posible que sobrevenga una situación de déficit de ventiladores hospitalarios que obligue a la utilización de equipos de una sola rama e incluso de aquellos diseñados para domicilio y para terapia de apnea de sueño.

\section{Protocolo de terapia}

En los pacientes con COVID-19 que se presentan con insuficiencia respiratoria hipoxémica, el primer paso será evaluar la respuesta a la oxigenoterapia (hasta $15 \mathrm{l} / \mathrm{min}$ ) o al oxígeno por cánula de alto flujo (desde $35 \mathrm{~L} / \mathrm{min}$ ). La monitorización puede ser con oximetría de pulso. Si la saturación de oxígeno $\left(\mathrm{SpO}_{2}\right)$ se mantiene bajo $93 \%$, escale el tratamiento a terapia CPAP a presión entre 8-10 $\mathrm{cmH}_{2} \mathrm{O}$. De haber una respuesta favorable, se apreciará una mejoría relativamente rápida de los parámetros respiratorios, dentro de la primera hora de conexión (Figura 3).

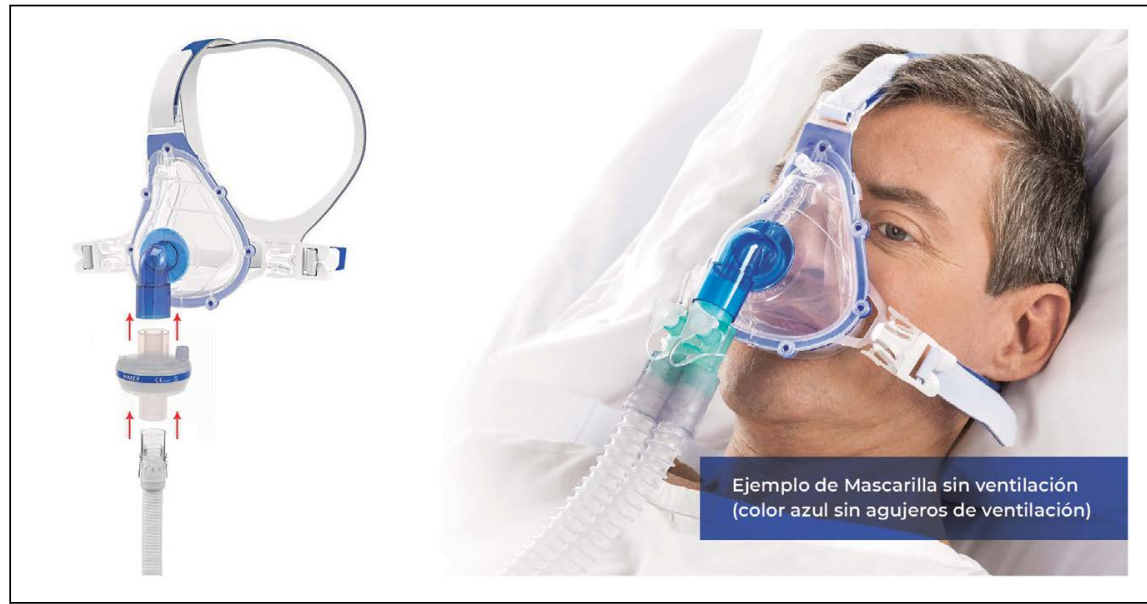

Figura 1. Configuración del circuito en equipos de ventilación no invasiva. Son 3 piezas: la máscara no ventilada (se reconoce por el codo azul) va conectada a un filtro HMEF o HEPA entre la máscara y el puerto espiratorio.
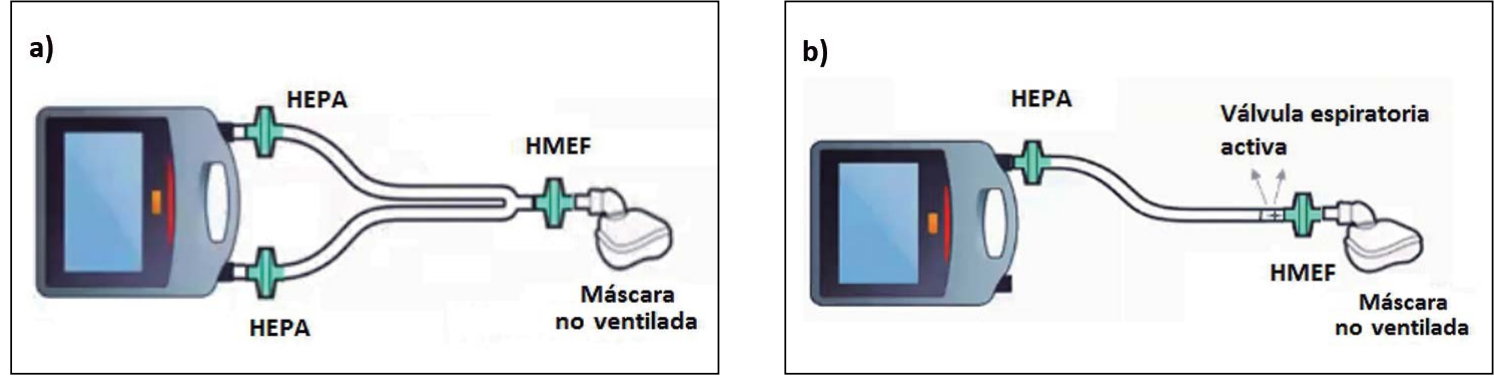

Figura 2. Configuración del circuito de ventilación no-invasiva. a) Ventilador a turbina de doble rama: Idealmente, utilizar 3 filtros viral/bacteriano: 1 HEPA conectado en la rama inspiratoria y otro en la rama espiratoria del circuito y 1 intercambiador de calor/humedad HME con filtro viral/bacteriano (HMEF) entre la máscara no ventilada y la Y del circuito. b) Equipos con usa sola rama (diseñados para uso hospitalario o domiciliario): Utilizar 2 filtros viral/ bacteriano: 1 HEPA conectado entre la rama inspiratoria y el ventilador y 1 filtro viral/bacteriano más intercambiador de calor/humedad (HMEF) antes del puerto espiratorio. 


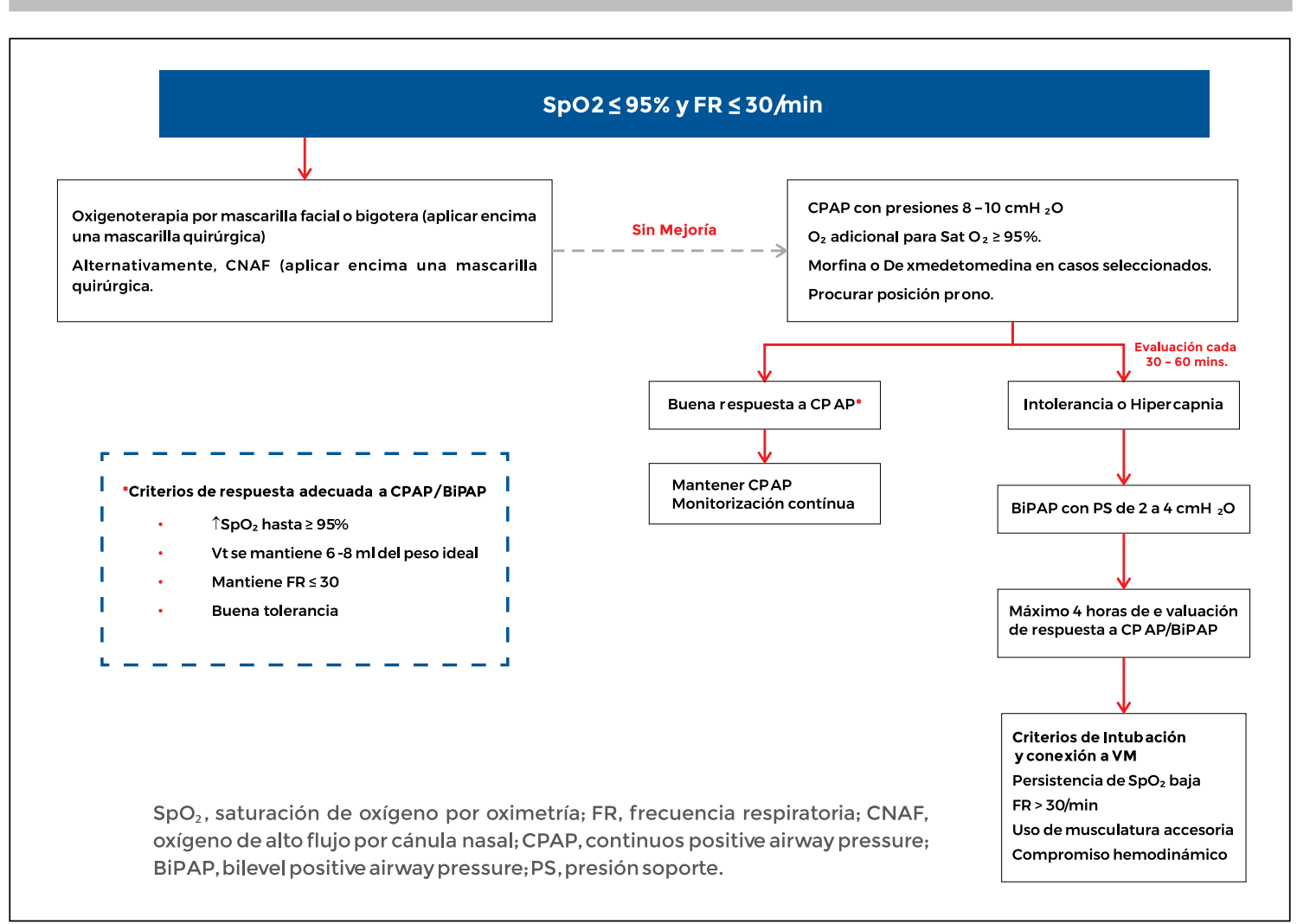

Figura 3. Protocolo de atención al paciente hospitalizado con COVID-19.

Si el paciente con terapia CPAP se queja de disnea o en caso de hipercapnia, utilice un modo con presión de soporte no mayor a $4 \mathrm{cmH}_{2} \mathrm{O}$. Mayores presiones aumentan la probabilidad de daño pulmonar inducido por volumen corriente excesivo $\mathrm{y}$, promueven dispersión de aerosol desde el paciente. Aunque el volumen corriente debe mantenerse entre $6-8 \mathrm{ml}$ por $\mathrm{kg}$ de peso ideal, esto suele ser difícil de lograr por el esfuerzo inspiratorio del paciente y porque las mediciones son imprecisas.

Hay un potencial beneficio de la posición prono bajo oxigenoterapia o terapia CPAP/ BiPAP que debiera evaluarse en cada paciente. El prono vigil a veces es difícil de tolerar por el paciente. Se sugiere monitorizar la respuesta a los 30-60 min. Si hay mejoría de los índices respiratorios (frecuencia respiratoria, $\mathrm{SpO}_{2}$ y disnea) y buena tolerancia del paciente, se puede prolongar la posición de prono en intervalos ajustados individualmente $(3-6 \mathrm{~h})^{13,14}$.

Una vez iniciada la terapia CPAP/BiPAP, no espere más de $2 \mathrm{~h}$ para definir que el paciente no ha respondido y prepárese para la intubación y conexión a VM con todas las precauciones necesarias.

\section{¿Qué índices monitorizar para definir una ade-} cuada respuesta a terapia CPAP/BiPAP?

- El paciente tolera la terapia y la presión positiva.

- No existe fuga de aire entre la máscara y la piel del paciente.

- $\mathrm{La} \mathrm{SpO}_{2}$ bajo terapia CPAP/BiPAP debe mantenerse entre $92-96 \%$.

- El volumen corriente debe mantenerse entre 6-8 $\mathrm{ml}$ por $\mathrm{kg}$ de peso ideal.

- La frecuencia respiratoria se mantiene $<35$ por minuto.

- No debe haber uso de musculatura respiratoria accesoria ni respiración paradójica.

\section{Bibliografía}

1.- FRAT JP, THILLE AW, MERCAT A, GIRAULT C, RAGOT S, PERBET S, et al. FLORALI Study Group, REVA Network. High-flow oxygen through nasal cannula in acute hypoxemic respiratory failure. N Engl $\mathrm{J}$ Med 2015; 372: 2185-96.

2.- PATEL BK, WOLFE KS, POHLMAN AS, HALL JB, KRESS JP. Effect of noninvasive ventilation delivered by helmet $v s$ face mask on the rate of endotracheal 
intubation in patients with acute respiratory distress syndrome: a randomized clinical trial. JAMA 2016; 315 : 2435-41.

3.- CHAWLA R, DIXIT SB, ZIRPE KG, CHAUDHRY D, KHILNANI GC, MEHTA Y, et al. ISCCM Guidelines for the use of non-invasive ventilation in acute respiratory failure in adult ICUs. Indian J Crit Care Med 2020; 24: S61-S81.

4.- ESQUINAS AM, EGBERT PRAVINKUMAR S, SCALA R, GAY P, SOROKSKY A, GIRAULT C, et al. International noninvasive mechanical ventilation in high-risk pulmonary infections: a clinical review. Eur Respir Rev 2014; 23: 427-38.

5.- SIMONDS AK, HANAK A, CHATWIN M, MORRELL MJ, HALL A, PARKER KH, et al. Evaluation of droplet dispersion during non-invasive ventilation, oxygen therapy, nebuliser treatment and chest physiotherapy in clinical practice: implications for management of pandemic influenza and other airborne infections. Health Technol Assess 2010; 14: 131-72.

6. FERIOLI M, CISTERNINO C, LEO V, PISANI L, PALANGE P, NAVA S. Protecting healthcare workers from SARS-CoV-2 infection: practical indications. Eur Respir Rev 2020; 29: 200068.

7. GATTINONI L, CHIUMELLO D, CAIRONI P, BUSANA M, ROMITTI F, BRAZZI L, et al. COVID-19 pneumonia: different respiratory treatment for different phenotypes? Intensive Care Med 2020 Apr 14;1-4.

8. Recomendaciones para pacientes usuarios de CPAP domiciliario durante la Pandemia COVID-19, Documento
Consenso de Recomendaciones para la Práctica de la Medicina del Sueño, con motivo de la Pandemia SARSCoV-2, COVID-19. Accedido el 23 de mayo 2020 en: https://sochimes.cl/RECOMENDACIONES_SOCHIMES_COVID-19.pdf.

9. XIE J, TONG Z, GUAN X, DU B, QIU H. Clinical Characteristics of Patients Who Died of Coronavirus Disease 2019 in China. JAMA Netw Open 2020; 3: e205619.

10. HUI DS, CHOW BK, LO T, NG SS, KO FW, GIN T, et al. Exhaled air dispersion during noninvasive ventilation via helmets and a total facemask. Chest 2015; 147: 1336-43.

11. HUI DS, CHOW BK, LO T, TSANG OTY, KO FW, NG SS, et al. Exhaled air dispersion during high-flow nasal cannula therapy versus CPAP via different masks. Eur Respir J 2019; 53: 1802339.

12. THYS F, LIISTRO G, DOZIN O, MARION E, RODENSTEIN DO. Determinants of $\mathrm{FiO}_{2}$ with oxygen supplementation during noninvasive two-level positive pressure ventilation. Eur Respir J 2002; 19: 653-7.

13. DING L, WANG L, MA W, HE H. Efficacy and safety of early prone positioning combined with HFNC or NIV in moderate to severe ARDS: a multi-center prospective cohort study. Critical Care 2020; 24: 114.

14. ELHARRAR X, TRIGUI T, DOLS A-M, TOUCHON F, MARTÍNEZ S, PRUD'HOMME E, et al. Use of prone positioning in nonintubated patients with $\mathrm{CO}$ VID-19 and hypoxemic acute respiratory failure. JAMA 2020; e208255.
Correspondencia a:

Dr. Matías Florenzano Valdés Instituto Nacional del Tórax J.M. Infante 717. Providencia Santiago.Chile.

Email: mflorenzano@gmail.com 